\title{
Retour sur « Faut-il être résolument amoderne? »
}

Jean-Luc Jamard

\section{OpenEdition}

\section{Journals}

Édition électronique

URL : https://journals.openedition.org/tc/5179

DOI : $10.4000 /$ tc. 5179

ISSN : 1952-420X

\section{Éditeur}

Éditions de l'EHESS

\section{Édition imprimée}

Date de publication : 30 juin 2010

Pagination : 712-714

ISSN : 0248-6016

\section{Référence électronique}

Jean-Luc Jamard, «Retour sur « Faut-il être résolument amoderne? » », Techniques \& Culture [En ligne], 54-55 | 2010, mis en ligne le 30 juin 2013, consulté le 29 septembre 2022. URL : http:// journals.openedition.org/tc/5179; DOI : https://doi.org/10.4000/tc.5179 


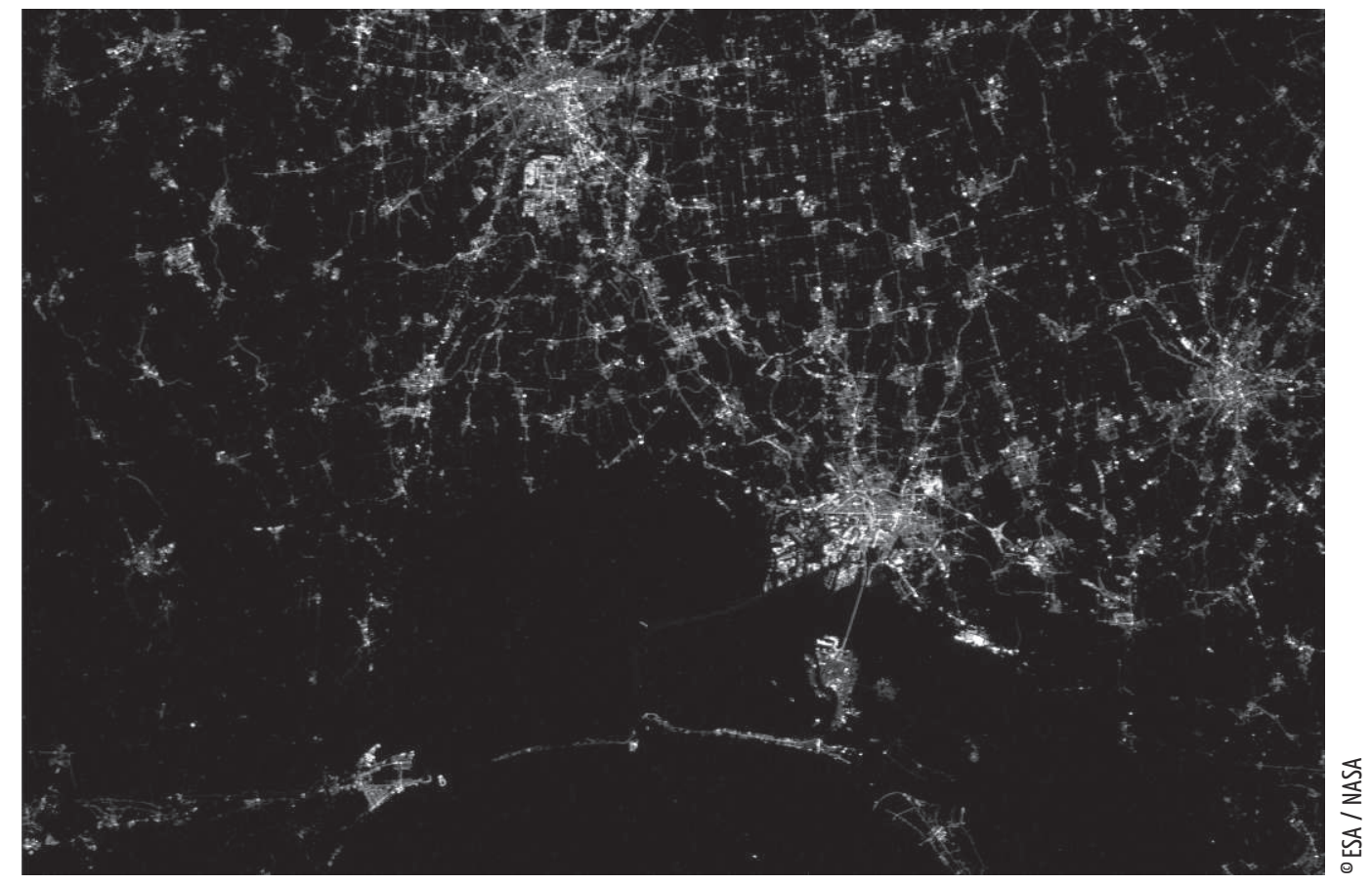




\section{«Faut-il être résolument amoderne?»}

«Que l'on ne se méprenne pas: loin de nous l'idée que les faits - ou la réalité - n'existent pas. Cela suffit à nous démarquer du relativisme. Nous affirmons seulement que cette "extériorité" est la conséquence du travail scientifique et non sa cause. »Ces phrases m’avaient, dès ma lecture de La vie de laboratoire ${ }^{1}$, un peu surpris. Non que je ne puisse admettre l'éventuel intérêt méthodologique de pareilles assertions. Mais, hélas pour ma pauvre tête, deux facteurs de perplexité allaient me faire adopter pour longtemps la posture du Penseur de Rodin.

Primo, d'après tous les bons auteurs et même quelques médiocres, il est plusieurs formes de relativisme. Je ne m'étendrai pas sur cette évidence, laquelle suffit en soi : il ne suffit pas de dire que la réalité (ou les faits) existe pour se démarquer du relativisme. Pinaillage superflu? Non, puisque lorsque mon texte fut écrit (1991), je voulais, entre autres intentions, contribuer à faire pièce aux relativismes de tous bords qui perfusaient dans certaines démarches anthropologiques. (Comme aujourd'hui encore, notamment si l'on se tourne vers la recherche anglo-saxonne.)

Or, voici le second point, c'est presque uniquement comme anthropologue que j'ai conçu l'argumentation. D'où mon insistance sur des données et raisonnements qui relèvent de la discipline intéressée. Et de là mes critiques concernant quelques inconséquences. N'étaient les évolutions des formules latouriennes - encore que... nous verrons -, ces critiques « internes », je ne les crois pas datées. J'en évoque très vite une illustration. Selon notre auteur, d'un côté, nature et société sont également " construites », partout et toujours; je suis prêt, en nuançant, à le lui concéder; ce sont les « Amodernes » (c'est-à-dire les sociétés « premières ») qui nous l'apprennent et ils mêlent nature et culture. Dès lors, soyons logiques, ceux-ci, comme nous mais autrement, construisent leurs mondes différemment suivant les populations (Latour passe outre); d'ailleurs en y réservant toujours 
- silence latourien - quelque contenu à la « non-culture » et aux « vraies choses », pas le même partout. De l'autre côté, les vérités que décèlent dans nature ou culture les diverses sciences afférentes sont le produit des victoires temporaires de leurs spécialistes lors de controverses: même remarque, mais alors soyons cohérents, c'est aussi le cas des vérités ethnologiques mutuellement controversées, donc variables, quant aux mondes exotiques. En conséquence, bien que fort brillant, Latour s'avère, sur ces chapitres, auto-contradictoire.

Chacun sait qu'il a beaucoup écrit depuis 1991 et c'est pourquoi, en toute logique, nombre de mes critiques « externes » d'alors apparaîtront datées ou obsolètes. Peutêtre; mais reste que jusqu'à ces temps-ci, n’a cessé de grandir la perplexité qui était la mienne voici vingt ans, quand je l'interrogeais in petto: Nous parlez-vous d'ontologie, d'épistémologie, de méthode? J'incline à penser que selon les circonstances, il saute en agile acrobate entre les trois, derrière le voile de sa rhétorique consommée. Sans doute ne serait-ce pas le seul des social scientists à osciller « ... comme un ludion, entre les divers niveaux de référence possibles », comme l'écrivit Lévi-Strauss ${ }^{2}$ à propos des anthropologues en général. Mais Latour le fait en virtuose. Est-ce délibéré, voire malhonnête? La question est hors jeu, et qu'on n'aille pas m'assimiler à ceux qui le rangent avec dédain parmi les mystificateurs ou les imposteurs. J'ai beaucoup appris en le lisant.

Rhétorique, disais-je. Dernière phrase de l'article ici présenté: « les débats que devrait susciter l'anthropologie des nouveaux dictyologues [s'annoncent divers et stimulants]. Même si (ou parce que) l'on y reconnaît souvent de bons vieux problèmes vêtus d'habits neufs. » Robert K. Merton avait déjà abordé ces problèmes dans les années 1940 et 1950 ; mais leurs habits neufs? Eh bien, c'est cela (quoiqu'il n'y ait pas que ça): une nouvelle et séduisante façon d'en parler. Voyez donc le dernier ouvrage en date de Latour: « Ou bien vous pratiquez la rhétorique, ou bien vous faites une démonstration. Entre avoir du bagout et avoir raison "pour de vrai", il faut, dit-on, choisir. [...] Aucune [distinction] n'est plus solidement retranchée. Et pourtant [...], aucune n'est plus contraire à l'évidence! ${ }^{3}$ » (violemment arrachée à son contexte, cette citation, par définition; lisez la suite du livre).

Ceci encore. En 1991, j'opposais, à l'analyse sémiotique par Latour d'un livre de Einstein sur la relativité, un modèle complémentariste « quantique » applicable, lui aussi, à l'étude des faits sociotechniques. Mais celui-ci était à entendre cum grano salis: Bohr contre Einstein... Quant aux techniques « proprement dites », je me tais, dans l'espoir que les lecteurs mis en appétit s'empressent d'aller dévorer mon texte réédité. 